\title{
Femtosecond lenticule extraction for correction of myopia: a 6 month follow-up study
}

This article was published in the following Dove Press journal:

Clinical Ophthalmology

6 June 2013

Number of times this article has been viewed

\author{
Ahmet Demirok' \\ Alper Agca ${ }^{2}$ \\ Engin Bilge Ozgurhan ${ }^{2}$ \\ Ercument Bozkurt ${ }^{2}$ \\ Ugur Celik ${ }^{2}$ \\ Ali Demircan ${ }^{2}$ \\ Nimet Burcu Guleryuz ${ }^{2}$ \\ Kadir İlker Cankaya ${ }^{2}$ \\ Omer Faruk Yilmaz ${ }^{3}$ \\ 'Department of Ophthalmology, \\ Medeniyet University, Istanbul, Turkey; \\ ${ }^{2}$ Beyoglu Eye Training and Research \\ Hospital, Istanbul, Turkey, ${ }^{3}$ Private \\ Practice, Istanbul, Turkey
}

Correspondence: Ugur Celik Beyoglu Eye Training and Research Hospital, Bereketzade camii Sok, 3442I, Kuledibi, Beyoglu, Istanbul, Turkey Tel +90 2I 2 25I 5900 Email h.ugurcelik@gmail.com
Aims: To report our initial experience with femtosecond lenticule extraction (FLEX) compared with femtosecond laser-assisted in situ keratomileusis (LASIK).

Settings and design: This was a prospective pilot study carried out at the Refractive Surgery Department of the Beyoglu Eye Training and Research Hospital, Istanbul, Turkey.

Materials and methods: Surgery was performed on both eyes of 14 consecutive patients with myopia or myopic astigmatism. Patients underwent FLEX in one eye and femtosecond LASIK (FemtoLASIK) in the other eye. The primary outcome was based on uncorrected distance visual acuity, corrected distance visual acuity, and spherical equivalent of the subjective manifest refraction, at 1 week, 1 month, and 6 months postsurgery. Statistical analyses were performed using PAWS Statistics 18. Unpaired Student's $t$-test was used to compare the groups.

Results: During the last follow-up visit (6 months postsurgery), the mean spherical was $-0.37 \pm 0.60$ diopters $(\mathrm{D})$ (range -1.00 to 0.50$)(P<0.001)$ and $-0.25 \pm 0.41 \mathrm{D}$ (range -0.88 to $0.12 \mathrm{D})(P<0.001)$ in the FLEX and FemtoLASIK eyes, respectively. The spherical was within $\pm 0.50 \mathrm{D}$ of the intended correction in ten (72\%) of the FLEX eyes and $12(86 \%)$ of the FemtoLASIK eyes $(P>0.05)$. No complications occurred during surgery or the postoperative period.

Conclusion: FLEX is a safe, effective, and predictable procedure for surgical correction of myopia. Refractive results were stabilized within the first postoperative week, and visual acuities were stabilized within the first month, comparable to FemtoLASIK.

Keywords: FLEX, femtosecond laser-assisted in situ keratomileusis

\section{Introduction}

Excimer laser refractive surgery, based on the stromal photoablation of the cornea, is currently the most popular refractive surgery procedure. The concept of generating a free intrastromal lenticule between two photodisruption planes and its mechanical removal for refractive correction was introduced by Ito et al in $1996 .{ }^{1}$ Early clinical studies were performed on a very limited number of eyes from a nonrepresentative cohort and provided inconclusive results. ${ }^{2,3}$

The VisuMax ${ }^{\circledR}$ Femtosecond System laser platform (Carl Zeiss Meditec AG, Jena, Germany) is the only commercially available femtosecond laser platform equipped to perform femtosecond lenticule extraction (FLEX) surgery. The procedure is called FLEX because it involves creating and then lifting a hinged femtosecond flap above the lenticule; if a flap is not created and the lenticule is extracted from a 3-4 mm side cut, the procedure is called a small-incision lenticule extraction (SMILE). Early refractive results using the VisuMax platform for SMILE and FLEX are encouraging. ${ }^{4-9}$ However, Shah and Shah 
found that refractive results stabilized within the first week after surgery but that visual recovery was slower. ${ }^{8}$ No detailed information is available in the literature regarding the amount of line loss at different follow-up periods. Moreover, there are no comparative studies between FLEX and femtosecond laserassisted in situ keratomileusis (FemtoLASIK). In the current study, we describe refractive results, efficacy, and safety of the FLEX procedure compared with that of the FemtoLASIK procedure.

\section{Materials and methods}

Surgery was performed on both eyes of 14 consecutive patients with myopia or myopic astigmatism. Under the care of two surgeons, each patient underwent FLEX in one eye and FemtoLASIK in the contralateral eye. This prospective pilot study was approved by the hospital's Ethics Committee, and all patients provided informed consent.

Patients older than 18 years of age with myopia or myopic astigmatism were included in the study. Additional inclusion criteria were: spherical equivalent (SE) $<10$ diopters (D), mesopic (4 lux) pupil size $\leq 6.5 \mathrm{~mm}$, residual stromal bed thickness $>300 \mu \mathrm{m}$, best corrected visual acuity of at least 20/25 in both eyes, no ocular disease other than the refractive error, a normal topographic pattern, regular retinoscopic reflex, corneal pachymetry $>500 \mu \mathrm{m}$ at the thinnest point, and stable refraction for at least 2 years.

All patients received the preoperative refractive surgical procedure routinely offered at the clinic. Visual acuity measurements were made using an illuminated ETDRS chart (Optec $^{\circledR} 3500$ Vision Tester; Stereo Optical Co, Santa Ana, CA, USA). Objective cycloplegic refraction was measured using an Auto Kerato-Refractometer KR-1 (Topcon Corp, Tokyo, Japan) with retinoscopy, in all patients. Corneal topography, dynamic infrared pupillography, ocular wavefront analysis, and corneal wavefront analysis were performed using the Sirius corneal topography and aberrometry system (Costruzioni Strumenti Oftalmici, Scandicci, Italy). Horizontal corneal diameter was measured using a IOLMaster 500 (Carl Zeiss Meditec). Intraocular pressure was measured with a Goldmann applanation tonometer (Haag streit Medical Products, Mason, Ohio, USA). All patients had detailed anterior and posterior segment examination using a slit lamp.

Immediately postsurgery, patients were evaluated with the slit lamp by the surgeon. Follow-up visits occurred at 1 week, 1 month, 3 months, and 6 months after the surgery. Objective and subjective refraction eye tests were performed, and uncorrected and best corrected distance visual acuities were recorded during all follow-up visits. Visual acuities were transformed to the logarithm of the minimum angle of resolution (LogMAR) prior to statistical analysis.

The VisuMax femtosecond laser platform was used for all the FLEX surgeries. This femtosecond laser platform creates four cleavage planes at a pulse repetition rate of $500 \mathrm{~Hz}$. The spot distance used in this study was $3 \mu \mathrm{m}$ for lamellar cuts and $2 \mu \mathrm{m}$ for the side cuts. The spot energy was set to $140-150 \mathrm{~nJ}$. The minimum lenticule side cut thickness was set to $15 \mu \mathrm{m}$, and the flap thickness was set to $110 \mu \mathrm{m}$. The lenticule side cut angle was $120^{\circ}$, and the flap side cut angle was $90^{\circ}$. The optical zone was $6.5 \mathrm{~mm}$, and the flap diameter was $7.5 \mathrm{~mm}$, with a $50^{\circ}$ superior hinge in all patients. The optical zone diameter is equal to the lenticule diameter in patients with purely spherical refractive error. However, if the patient has astigmatism, the software adds a standard $0.1 \mathrm{~mm}$ transition zone to convert the oval lenticule into a circle.

The VisuMax femtosecond laser platform was used to create the flaps for all the FemtoLASIK patients. A flap diameter of $8.5 \mathrm{~mm}$ and thickness of $110 \mu \mathrm{m}$ were intended. Excimer laser treatment was performed using the Amaris $750 \mathrm{~s}$ Excimer Laser platform (Schwind eye-tech-solutions GmbH and Co KG, Kleinostheim, Germany). All treatments were calculated using the ORK-CAM software module (Schwind eye-tech-solutions GmbH and Co KG). A $6.5 \mathrm{~mm}$ optical zone was used for ablation. A variable transition size, automatically provided by the laser, was used for the planned refractive correction in the myopic and myopic astigmatic eyes $(6.7 \mathrm{~mm}$ to $8.6 \mathrm{~mm})$. The laser works at a true repetition rate of $750 \mathrm{~Hz}$ and produces a beam size of $0.54 \mathrm{~mm}$ fullwidth at half-maximum, with super Gaussian spot profile. ${ }^{10}$ High-speed eye tracking (pupil and limbus tracker with cyclotorsional tracking) with a $1050 \mathrm{~Hz}$ acquisition rate was completed within a latency time of $3 \mathrm{~ms} .{ }^{11,12}$

Table I Preoperative refractive characteristics of the patients

\begin{tabular}{|c|c|c|c|c|}
\hline & \multicolumn{2}{|l|}{ FLEX } & \multicolumn{2}{|c|}{ FemtoLASIK } \\
\hline & Mean \pm SD & Range & Mean \pm SD & Range \\
\hline Sphere* & $-4.26 \pm 1.52$ & $\begin{array}{l}-1.00 \text { to } \\
-5.75\end{array}$ & $-4.01 \pm 1.71$ & $\begin{array}{l}-1.00 \text { to } \\
-6.75\end{array}$ \\
\hline Cylinder** & $-0.94 \pm 1.12$ & $\begin{array}{l}0.00 \text { to } \\
-3.00\end{array}$ & $-1.14 \pm 0.96$ & $\begin{array}{l}0.00 \text { to } \\
-2.75\end{array}$ \\
\hline SE*** & $-4.74 \pm 1.60$ & $\begin{array}{l}-1.75 \text { to } \\
-6.75\end{array}$ & $-4.58 \pm 1.49$ & $\begin{array}{l}-1.50 \text { to } \\
-7.00\end{array}$ \\
\hline $\begin{array}{l}\text { Mesopic pupil } \\
\text { diameter (mm) }\end{array}$ & $5.84 \pm 0.78$ & $\begin{array}{l}4.96 \text { to } \\
6.45\end{array}$ & $5.32 \pm 0.80$ & $\begin{array}{l}4.36 \text { to } \\
6.50\end{array}$ \\
\hline
\end{tabular}

Notes: *Spherical component of the manifest refraction in the negative cylinder notation; **cylindrical component of the manifest refraction in the negative cylinder notation; ***spherical equivalent of the manifest refraction.

Abbreviations: FLEX, femtosecond lenticule extraction; FemtoLASIK, femtosecond laser-assisted in situ keratomileusis; SD, standard deviation; SE, spherical equivalent. 
Table 2 Preoperative refractive characteristics of right and left eyes

\begin{tabular}{llllll}
\hline & \multicolumn{1}{l}{ Right } & & & Left \\
\cline { 2 - 3 } \cline { 6 - 6 } & Mean \pm SD & Range & & Mean \pm SD & Range \\
\hline Sphere* & $-4.21 \pm 1.52$ & -1.00 to & & $-4.11 \pm 1.74$ & -1.00 to \\
& & -6.75 & & -6.00 \\
Cylinder** & $-1.05 \pm 1.07$ & 0.00 to & $-1.03 \pm 1.02$ & 0.00 to \\
& & -3.00 & & -2.75 \\
SE*** & $-4.67 \pm 1.57$ & -1.88 to & $-4.57 \pm 1.51$ & -1.50 to \\
& & -7.00 & & -6.50 \\
Mesopic pupil & $5.39 \pm 0.78$ & 4.36 to & & $5.42 \pm 0.83$ & 4.66 to \\
diameter $(\mathrm{mm})$ & & 6.35 & & 6.50 \\
\hline
\end{tabular}

Notes: *Spherical component of the manifest refraction in the negative cylinder notation; ${ }^{* *}$ cylindrical component of the manifest refraction in the negative cyclinder notation; ***spherical equivalent of the manifest refraction.

Abbreviations: SD, standard deviation; SE, spherical equivalent.

The FLEX procedure was performed first. After standard sterile draping of the eye, a speculum was inserted. The patient was asked to look at the internal fixation light while the surgeon, looking through the surgical microscope, adjusted the position of the eye in relation to the curved patient interface, using a joystick. Once the patient interface was centered on the pupil and a sufficient amount of contact was achieved, the surgeon activated the suction mechanism incorporated in the patient interface. Once the eye was immobilized, the delivery of the femtosecond laser pulses was initiated. The time from the beginning of the femtosecond laser pulses to the release of suction took approximately 30 seconds. After the femtosecond dissection planes were created, the patient bed was repositioned directly under the operating microscope for the

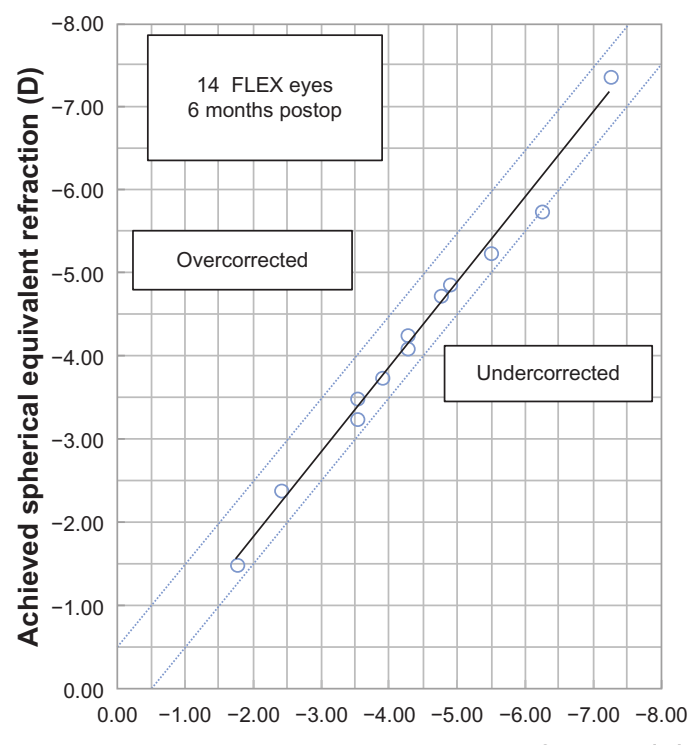

Attempted spherical equivalent refraction (D) rest of the surgery. A Katena Thorlakson Z-LASIK ${ }^{\mathrm{TM}}$ flap lifter (Katena Products Inc, Denville, NJ, USA) was used to separate the anterior surface of the lenticule from the overlying stroma and lift the flap. The lenticule was then separated from the underlying stroma using the same spatula, and it was removed manually with Katena Buratto LASIK Flap Forceps (Katena Products Inc). The stromal bed was washed with a balanced salt solution (Isolyte $\mathrm{S}^{\circledR}$, Eczacıbaşı Baxter, Turkey), and the flap was repositioned.

For FemtoLASIK surgery, each procedure was performed using established standard techniques. Under topical anesthesia and standard draping, a lid speculum was used to retract the eyelids. A superior hinged, $110 \mu \mathrm{m}$-thick flap was created using the VisuMax femtosecond laser. The patient was then transported to the patient bed of the Amaris $750 \mathrm{~S}$ excimer laser platform, and laser ablation was performed. After ablation, the flap was carefully repositioned. After surgery, all patients received a topical antibiotic for 5 days and a topical steroid for 2 weeks. Artificial tears were prescribed for at least 1 month.

All visual acuities were recorded as the total number of identified letters and the corresponding Snellen acuities. Mean visual acuities were determined by calculating the geometric mean with standard deviation, stated in LogMAR format as defined by Holladay and Prager. ${ }^{13}$ Repeated measures analysis of variance (RANOVA) was used to compare visual acuities and SE of refractive results in each group at different follow-up visits. A $P$-value $<0.05$ was considered statistically significant. Paired samples $t$-test with a Bonferroni correc-

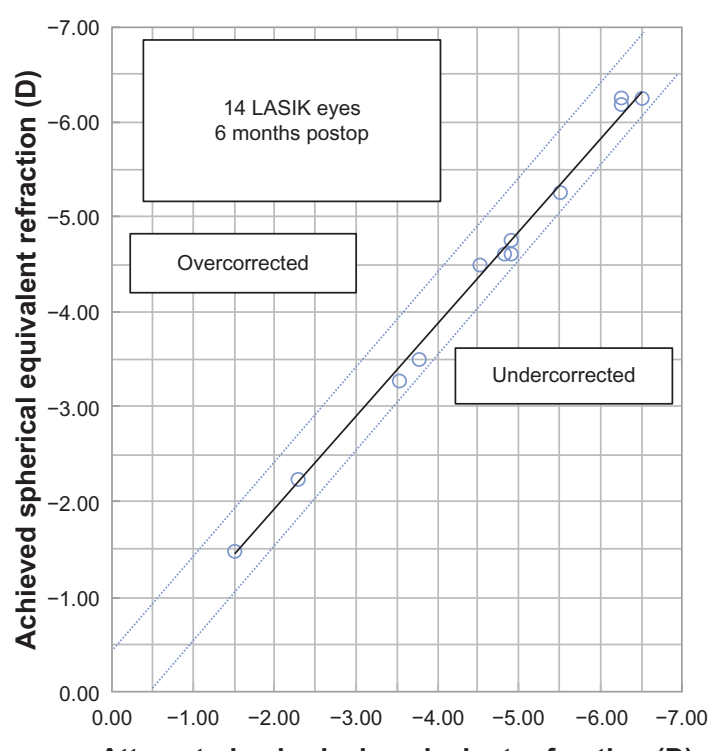

Attempted spherical equivalent refraction (D)

Figure I Scatterplot of the achieved refractive correction versus intended refractive correction.

Abbreviations: FLEX, femtosecond lenticule extraction; LASIK, laser-assisted in situ keratomileusis; D, diopters. 

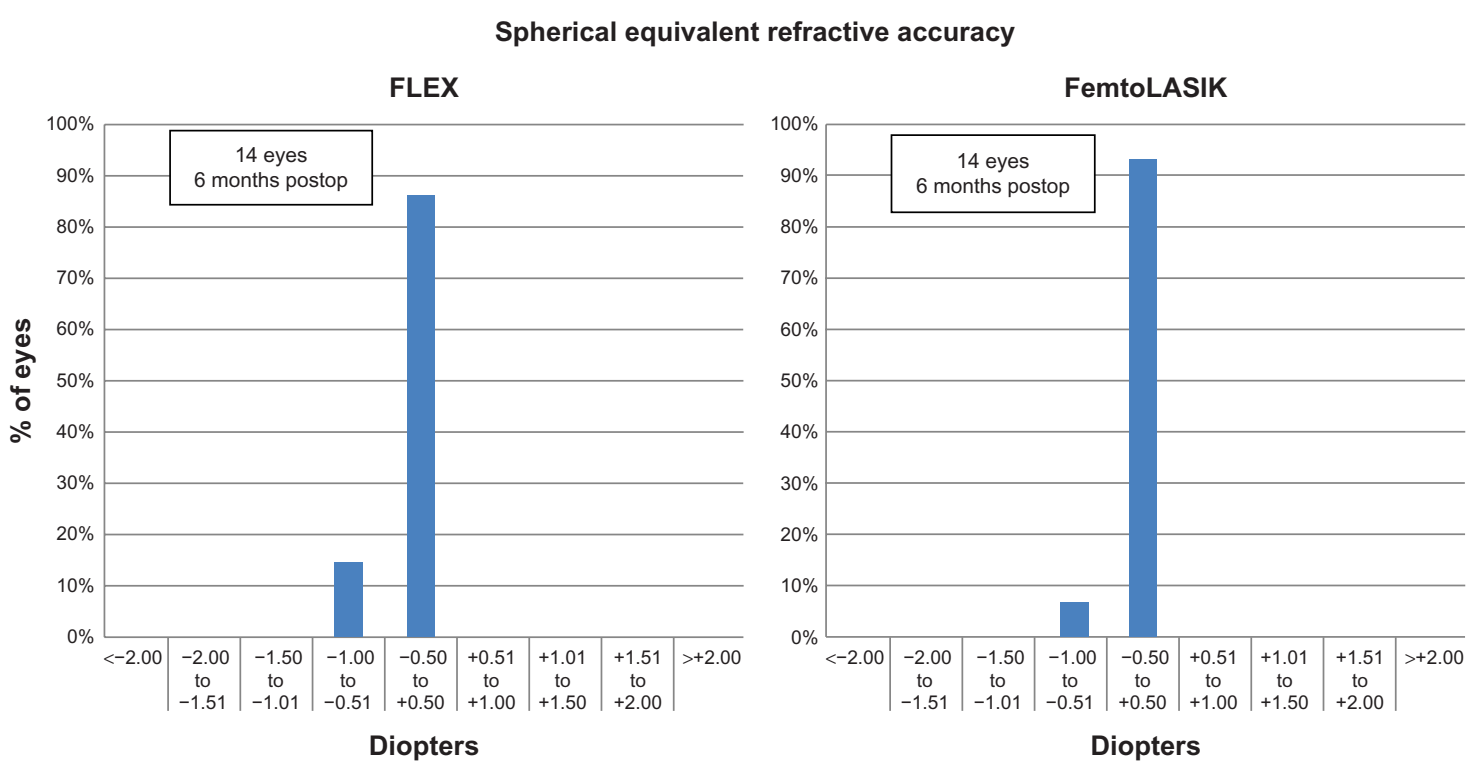

Figure 2 Difference between achieved correction and intended correction at 6 months postsurgery.

Abbreviations: FLEX, femtosecond lenticule extraction; FemtoLASIK, femtosecond laser-assisted in situ keratomileusis.

tion was used for post hoc analysis. Independent Samples $t$-test was used to compare the groups. All analyses were completed using PASW Statistics 18 (IBM, Armonk, NY, USA), and graphics were generated with Microsoft Excel 2007 (Microsoft Corp, Redmond, WA, USA)

\section{Results}

The study enrolled 28 eyes of 14 consecutive patients. The mean age of the four men and ten women was $27.3 \pm 7.9$ years, ranging from 18 to 42 years of age. Refractive characteristics of the patients are summarized in Table 1. The baseline refractive characteristics were similar for both eyes in the patients (Table 2).

The mean SE was $-0.37 \pm 0.60 \mathrm{D}$ (range -0.88 to 0.50 ) $(P<0.001)$ and $-0.25 \pm 0.41 \mathrm{D}$ (range -1.00 to $0.12 \mathrm{D})$ $(P<0.001)$ in the FLEX and FemtoLASIK eyes, respectively. Figure 1 shows the scatterplot of the achieved refractive correction versus the intended refractive correction with a corresponding regression line, at 6 months. The SE was within $\pm 0.50 \mathrm{D}$ of the intended correction in $86 \%$ of the FLEX eyes, and in $100 \%$ within $\pm 1.00 \mathrm{D}$. The intended correction was achieved in 12 eyes in the FLEX group, and 13 eyes in the FemtoLASIK group (Figure 2). The preoperative and postoperative refractive astigmatism of the patients are shown in Table 3 . The stability of the refractive correction did not change after the 3 months, in both groups (Figure 3).

The mean differences between the intended and achieved corrections were not statistically significant between groups at any of the follow-up visits $(P>0.05)$ (Table 4$)$. The differences of the mean uncorrected distance visual acuity
(UDVA) between groups at follow-up visits were also not statistically significant $(P>0.05)$ (Table 5).

Four eyes (29\%) lost one line, while one eye (7\%) lost two lines of corrected distance visual acuity (CDVA) at week one in the FLEX group. Seven eyes (50\%) lost one line, while one eye (7\%) lost two lines of CDVA at week 1 , in the FemtoLASIK group. However, at 1 month, 3 months, and 6 months postsurgery, no eye had lost one or more lines of CDVA (Figure 4).

\section{Discussion}

Two excimer laser-based refractive surgery modalities are now in widespread use: LASIK and photorefractive keratectomy (PRK). ${ }^{14,15}$ Between these, LASIK is the more popular, mainly because of faster visual rehabilitation and a more comfortable postoperative period. ${ }^{14}$ FLEX has recently become an alternative procedure. ${ }^{4,5}$ FLEX is based on the same concept as LASIK, which involves removal of a refractive lenticule from corneal stroma. In LASIK, the lenticule is photoablated spot by spot with the excimer laser.

Table 3 Mean uncorrected distance visual acuities

\begin{tabular}{lll}
\hline Follow-up visit & \multicolumn{2}{l}{ Mean cylindrical values } \\
\cline { 2 - 3 } & FLEX & FemtoLASIK \\
\hline Preoperative & $-0.94 \pm 1.12$ & $-1.14 \pm 0.96$ \\
Week I & $-0.37 \pm 0.38$ & $-0.35 \pm 0.37$ \\
Month I & $-0.32 \pm 0.40$ & $-0.28 \pm 0.35$ \\
Month 3 & $-0.30 \pm 0.36$ & $-0.26 \pm 0.33$ \\
Month 6 & $-0.35 \pm 0.40$ & $-0.32 \pm 0.34$ \\
\hline
\end{tabular}

Abbreviations: FLEX, femtosecond lenticule extraction; FemtoLASIK, femtosecond laser-assisted in situ keratomileusis. 
The stability of the refractive correction

FLEX

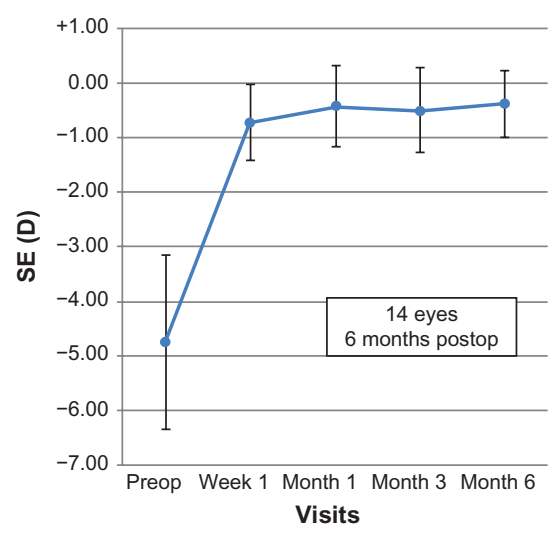

FemtoLASIK

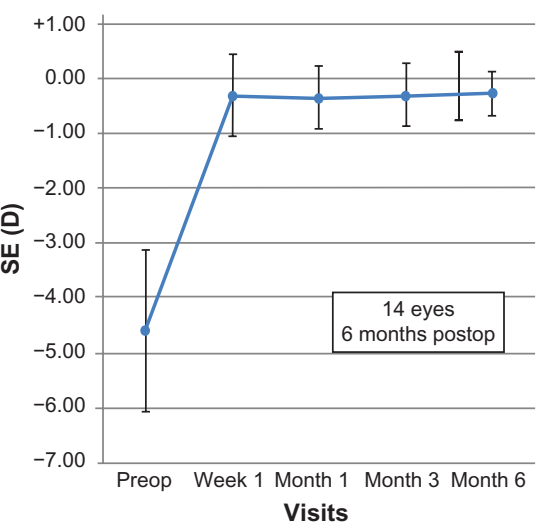

Figure 3 Stability of the spherical equivalent of subjective manifest refraction.

Abbreviations: FLEX, femtosecond lenticule extraction; FemtoLASIK, femtosecond laser-assisted in situ keratomileusis; SE, spherical equivalent; D, diopters.

However, in lenticule extraction, the lenticule is separated from the remaining stroma with photodisruption planes and removed manually as a single piece. With the excimer laser platforms, it is not possible to photoablate the intrastromal lenticule without lifting the anterior stromal tissue as a flap.

FLEX is a very straightforward procedure, with essentially no learning curve for a surgeon who is familiar with FemtoLASIK surgery. Sekundo et $\mathrm{al}^{4}$ reported the first results of FLEX using the VisuMax platform. They operated on ten eyes of ten patients, but only $40 \%$ of the eyes were within $\pm 0.50 \mathrm{D}$ of the intended correction $(90 \%$ were within $\pm 1.00 \mathrm{D}$ ). In a larger series of patients published in 2010, Blum et $\mathrm{al}^{5}$ also reported better results. They reported that $74 \%$ of patients were within $\pm 0.50 \mathrm{D}$. Since a prototype of the device and different energy settings were used in those two studies, their results cannot be directly compared with the current study results, which were significantly better. We used the latest generation of the VisuMax platform, with a $500 \mathrm{kHz}$ spot repetition rate, $3 \mu \mathrm{m}$ spot distance, and 140 nJ spot energy.

Table 4 The mean of the differences between intended and achieved corrections

\begin{tabular}{llll}
\hline Follow up visit & \multicolumn{2}{l}{ The mean of the difference* (D) } & P-value \\
\cline { 2 - 3 } & FLEX & FemtoLASIK & \\
\hline Week I & $-0.24 \pm 0.27$ & $-0.14 \pm 0.39$ & $0.4 I 1$ \\
Month I & $-0.31 \pm 0.32$ & $-0.29 \pm 0.31$ & 0.888 \\
Month 3 & $-0.31 \pm 0.36$ & $-0.28 \pm 0.32$ & 0.791 \\
Month 6 & $-0.29 \pm 0.30$ & $-0.25 \pm 0.30$ & 0.594 \\
\hline
\end{tabular}

Notes: *Achieved correction - intended correction

Abbreviations: FLEX, femtosecond lenticule extraction; FemtoLASIK, femtosecond laser-assisted in situ keratomileusis; D, diopters.
Results from studies by Shah and Shah, ${ }^{8}$ and Ang et al ${ }^{9}$ are consistent with those of the present study. They used a spot energy of approximately $160 \mathrm{~nJ}$ and reported that $95 \%$ of their patients were within $\pm 0.50 \mathrm{D}$ of the intended correction at 6 months (when the current recommended scanning trajectory of the VisuMax platform was used). They observed that refractive results stabilized within the first week but that visual recovery was slower.

There is no detailed information in the literature regarding the amount of line loss that occurs at different follow-up periods. Only Shah and colleagues have reported the percentage of patients who lost two or more lines during the early postoperative period. ${ }^{8}$ They reported that $5 \%$ of patients had lost two or more lines at 1 week postsurgery but that no patients lost two or more lines after 6 months. At 1 week postsurgery, $35 \%$ of patients in the FLEX group had a loss of two or more lines of CDVA. However, none of the patients had loss of two or more lines of CDVA at the 1-month, 3-month, and 6-month visits, and FLEX may be considered safe in this regard.

Table 5 Mean uncorrected distance visual acuity (UDVA)

\begin{tabular}{llll}
\hline Follow up visit & \multicolumn{2}{l}{ Mean UDVA (LogMAR \pm SD) } & \multirow{2}{*}{ P-value } \\
\cline { 2 - 3 } & FLEX & FemtoLASIK & \\
\hline Preoperative & $\mathrm{I} .32 \pm 0.40$ & $1.39 \pm 0.40$ & 0.660 \\
Week I & $0.22 \pm 0.23$ & $0.19 \pm 0.20$ & 0.699 \\
Month I & $0.20 \pm 0.25$ & $0.11 \pm 0.14$ & 0.242 \\
Month 3 & $0.15 \pm 0.20$ & $0.09 \pm 0.13$ & 0.314 \\
Month 6 & $0.02 \pm 0.03$ & $0.02 \pm 0.04$ & 0.704 \\
\hline
\end{tabular}

Notes: The differences between the groups at month I, month 3, and month 6 were not statistically significant.

Abbreviations: FLEX, femtosecond lenticule extraction; FemtoLASIK, femtosecond laser-assisted in situ keratomileusis; LogMAR, logarithm of the minimum angle of resolution; SD, standard deviation. 
Change in Snellen lines of corrected visual acuity
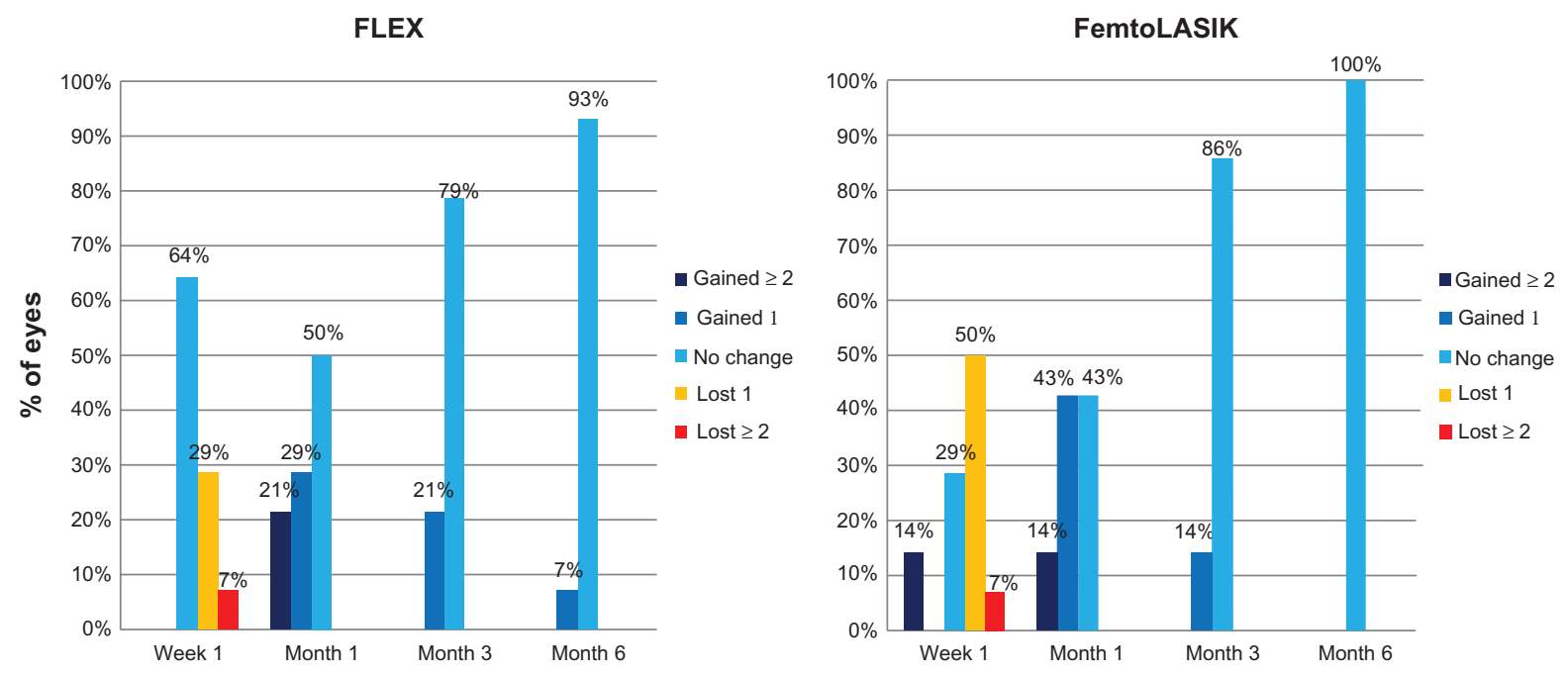

Figure 4 Change in Snellen lines of corrected distance visual acuity over time.

Abbreviations: FLEX, femtosecond lenticule extraction; FemtoLASIK, femtosecond laser-assisted in situ keratomileusis

No statistically significant differences were observed in terms of achieved refractive correction after 1 week and 1 month. However, the mean UDVA was significantly worse at 1 week postsurgery. At 1 month, $95 \%$ of patients had UDVA $\geq 20 / 25$, which was a considerable improvement from the $65 \%$ of patients with UDVA $\geq 20 / 25$ at 1 week. The presence of worse UDVA despite the same amount of achieved refractive correction suggests that the visual acuity was delayed despite the successful refractive correction. This incompatibility was not observed in the FemtoLASIK group. Comparisons of achieved correction after 1 week and later visits were not statistically significant. Compatible with the statistically insignificant refractive difference, the UDVA were also similar $(P<0.05)$.

Despite the slightly delayed visual recovery in the FLEX eyes, the refractive results and final visual acuities were similar in both groups. In the FLEX group, the SE was within $\pm 0.50 \mathrm{D}$ of the intended correction, in $86 \%$ of eyes, and it was within $\pm 1.00 \mathrm{D}$ of the intended correction, in all the eyes. Some studies have reported $>95 \%$ of myopic patients to be within $\pm 0.50 \mathrm{D}$ of the intended correction after LASIK surgery; however, the results vary greatly depending on patient selection and the excimer laser platform. ${ }^{16}$ Contrary to other published studies, ${ }^{4-9}$ there was a slight tendency for undercorrection, and none of the cases were found to be overcorrected. This difference may be due to differences in preoperative refractive errors, since the current study included eyes with the lowest preoperative SE, while previous studies did not. ${ }^{4-9}$

With respect to intraoperative complications, no suction loss or development of an excessive opaque bubble layer were noted. However, drying of the corneal epithelial surface during the actual surgical procedure greatly reduced the quality of the stromal cuts. No significant postoperative complications occurred in any case.

In conclusion, this study shows that FLEX is a safe and effective alternative to LASIK. The refractive results are comparable between both procedures; however, visual recovery is slightly slower after the FLEX procedure. The quality of stromal cuts was adequate for dissecting and removing the lenticule. Future optimization of laser energy, spot size, and spacing will potentially further simplify the removal of the lenticule and speed up visual recovery.

\section{Disclosure}

The authors report no conflicts of interest in this work.

\section{References}

1. Ito M, Quantock AJ, Malhan S, Schanzlin DJ, Krueger RR. Picosecond laser in situ keratomileusis with a 1053-nm Nd:YLF laser. J Refract Surg. 1996;12(6):721-728.

2. Krueger RR, JuhaszT, Gualano A, Marchi V.The picosecond laser for nonmechanical laser in situ keratomileusis. J Refract Surg. 1998;14(4):467-469.

3. Ratkay-Traub I, Ferincz IE, Juhasz T, Kurtz RM, Krueger RR. First clinical results with the femtosecond neodynium-glass laser in refractive surgery. J Refract Surg. 2003;19(2):94-103.

4. Sekundo W, Kunert K, Russman C, et al. First efficacy and safety study of femtosecond lenticule extraction for the correction of myopia: sixmonth results. J Cataract Refract Surg. 2008;34(9):1513-1520.

5. Blum M, Kunert K, Schröder M, Sekundo W. Femtosecond lenticule extraction for the correction of myopia: preliminary 6-month results. Greafes Arch Clin Exp Ophthalmol. 2010;248(7):1019-1027.

6. Sekundo W, Kunert K, Blum M. Small incision corneal refractive surgery using the small incision lenticule extraction (SMILE) procedure for the correction of myopia and myopic astigmatism: results of a 6-month prospective study. Br J Ophthalmol. 2011;95(3):335-339. 
7. Shah R, Shah S, Sengupta S. Results of small incision lenticule extraction: all-in-one femtosecond laser refractive surgery. $J$ Refract Surg. 2011;37(1):127-137.

8. Shah R, Shah S. Effect of scanning patterns on the results of femtosecond laser lenticule extraction refractive surgery. J Cataract Refract Surg. 2011;37(9):1636-1647.

9. Ang M, Chaurasia SS, Angunawela RI, et al. Femtosecond lenticule extraction (FLEx): clinical results, interface evaluation, and intraocular pressure variation. Invest Ophthalmol Vis Sci. 2012;53(3):1414-1421.

10. Huang D, Arif M. Spot size and quality of scanning laser correction of higher-order wavefront aberrations. J Cataract Refract Surg. 2002;28(3):407-416.

11. Arba-Mosquera S, Merayo-Lloves J, de Ortueta D. Clinical effects of pure cyclotorsional errors during refractive surgery. Invest Ophthalmol Vis Sci. 2008;49(11):4828-4836.
12. Bueeler M, Mrochen M. Simulation of eye-tracker latency, spot size, and ablation pulse depth on the correction of higher order wavefront aberrations with scanning spot laser systems. J Refract Surg. 2005;21(1):28-36.

13. Holladay JT, Prager TC. Mean visual acuity. Am J Ophthalmol. 1991;111(3):372-374.

14. Ghadhfan F, Al-Rajhi A, Wagoner MD. Laser in situ keratomileusis versus surface ablation: visual outcomes and complications. J Cataract Refract Surg. 2007;33(12):2041-2048.

15. Shortt AJ, Bunce C, Allan BD. Evidence for superior efficacy and safety of LASIK over photorefractive keratectomy for correction of myopia. Ophthalmology. 2006;113(11):1897-1908.

16. Blum M, Kunert K, Gille A, Sekundo W. LASIK for myopia using the Zeiss VisuMax femtosecond laser and MEL 80 excimer laser. J Refract Surg. 2009;25(4):3506.
Clinical Ophthalmology

\section{Publish your work in this journal}

Clinical Ophthalmology is an international, peer-reviewed journal covering all subspecialties within ophthalmology. Key topics include: Optometry; Visual science; Pharmacology and drug therapy in eye diseases; Basic Sciences; Primary and Secondary eye care; Patien Safety and Quality of Care Improvements. This journal is indexed on

Submit your manuscript here: http://www.dovepress.com/clinical-ophthalmology-journal

\section{Dovepress}

PubMed Central and CAS, and is the official journal of The Society of Clinical Ophthalmology (SCO). The manuscript management system is completely online and includes a very quick and fair peer-review system, which is all easy to use. Visit http://www.dovepress.com/ testimonials.php to read real quotes from published authors. 